\title{
ORAL REHABILITATION OF PATIENT WITH SICKLE CELL ANEMIA AND DENTAL ANOMALY: CASE REPORT
}

\author{
Dalia A. Abuelenain*
}

\begin{abstract}
Sickle cell anemia patients with dental anomalies represent a difficult challenge for the prosthetic dentist. Proper treatment planning with the medical and dental management of these patients are important prerequisites for successful results. This case report describes a full-mouth rehabilitation of a sickle cell anemia patient with worn-down dentition including the treatment planning, medical consultation, correction of vertical dimensions of occlusion, preparation, and restoration with porcelain fused to metal crowns.
\end{abstract}

KEY WORDS: Sickle cell anemia, Vertical dimensions of occlusion, porcelain fused to metal, worn-down dentition.

\section{INTRODUCTION}

Sickle cell anemia (SCA) is a genetic disease caused by a defect in chromosome II. The defect results in an amino acid substitution in the [3-hemoglobin chain of red blood cells (RBCs)], producing a homozygous state of the abnormal hemoglobin $\mathrm{S}(\mathrm{Hb} \mathrm{S})^{(1-3)}$. An alteration occurs in the DNA molecule which will result in a physiological change that causes the sickle-shaped red blood cells production. The sickle-shaped cells are the result of the hemoglobin $\mathrm{S}$ being deoxygenated. Further deoxygenation will occur due to the decreased affinity of oxygen to the abnormal hemoglobin, resulting in more sickle-shaped cells production ${ }^{(3)}$. This will cause microvasculature erythrostasis, or obstruction, leading to vasocclusion and multiple organ damages ${ }^{(2,4)}$. Clinically manifested in the form of bacterial infections, hemolytic anemia, painful vast-occlusive crises $^{(1)}$, and chronic hyperbilirubinemia ${ }^{(5)}$. $\mathrm{Hb} \mathrm{S}$ is found mainly in individuals of African, Middle Eastern or Indian ethnicity ${ }^{(6)}$.

Common oral findings associated with the disease include radiographic changes, delayed eruption, mucosal pallor, and anesthesia of the mandibular nerve, mandibular osteomyelitis, asymptomatic pulpal necrosis and dental hypoplasia $^{(1,4,6-11)}$. Dental management of patients with sickle cell anemia requires consultation with the patient hematologist and close interaction and cooperation before and during dental treatment ${ }^{(6-11)}$ 


\section{Case report}

A 20-years old female patient was referred to medically compromise dental patient's clinic in king Abdulaziz University Hospital, Faculty of dentistry, Jeddah, Saudi Arabia, for examination, evaluation and treatment of worn-down dentition. The medical history revealed that the patient is suffering from sickle cell anemia and physical condition of the patient was normal with generalized moderate weakness. The family history of the patient revealed that the patient mother and sisters are also affected by the same dental condition.

Dental examination revealed that there are severe attrition of lower anterior and posterior teeth with exposed dentin, generalized microdontia. The enamel layer was very thin and the cuspal structure was completely absent in the occlusal portion of molars and lower anterior teeth, which were most severely affected. In addition, the teeth exhibited short clinical crowns and large spaces between teeth due to small and missing dentition and the gingival hyperplasia, especially in the maxillary segment (Fig.1). The patient's vertical dimensions of occlusion (VDO) were reduced and the interocclusal rest space was increased due to the severe attrition in the molar area. The patient had fair oral hygiene. Intraoral photographs and panoramic $\mathrm{x}$-ray were obtained before treatment for proper diagnosis and treatment planning. Radiographic evaluation showed that the roots of the teeth had large pulp chamber that would increase the risk of bleeding during root canal treatment.

The treatment plan was developed to restore masticatory function, lost vertical dimensions and aesthetics. The treatment plan was discussed with the patient and the different options were explained in details and patient consent was obtained. The confirmed plan included medical consultation, crown lengthening of the molar and premolar upper and lower teeth, root canal treatment of the teeth with severe attrition, raising the vertical dimension of occlusion and construction of metal ceramic restorations for all teeth.

Antibiotic coverage and blood transfusion before each dental surgery appointment were recommended by patient hematologist after medical consultation. Following dental prophylaxis and oral hygiene instructions, complete maxillary and mandibular arch impressions were made using irreversible hydrocolloid (Kromalgin Piu; Vannini dental industry, Italy). Diagnostic casts were fabricated and they were mounted on a semi-adjustable articulator (Whip Mix; Model 8500, Whip Mix Corp, Louisville, USA) with a face bow transfer (Quick mount face bow; Model 8645, Whip Mix Corp, Louisville, USA) and a centric relation record using bite registration material (Occlufast Rock Imperceptible; Zhermack clinical, Italy). Diagnostic preparation and wax-up were done on the diagnostic models to evaluate the amount of tooth reduction for planned metal-ceramic restorations (Fig 2).

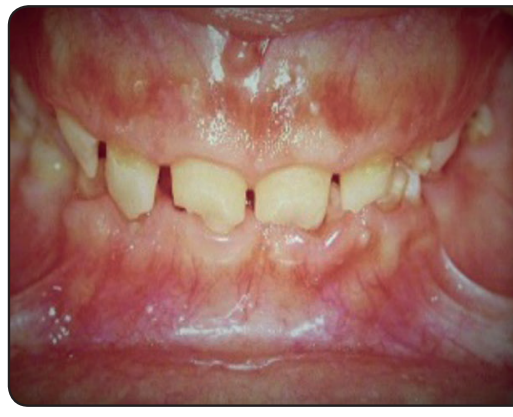

(a)

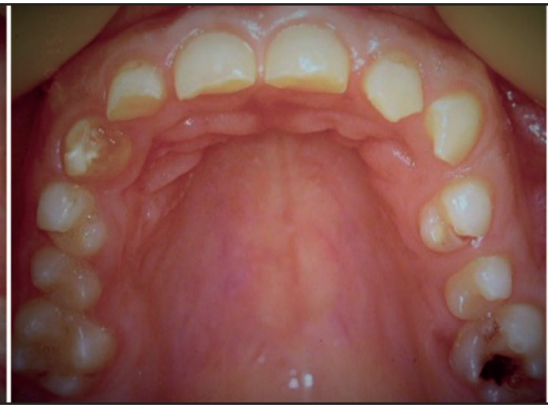

(b)

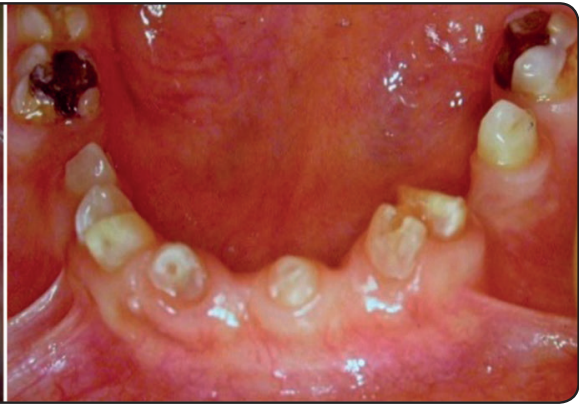

(c)

Fig. (1) Pre-treatment intra-oral views (a) centric occlusion, (b) maxillary arch and (c) mandibular arch. 
Analysis of the diagnostic setup revealed insufficient interocclusal space for fixed prostheses. VDO was increased by $4 \mathrm{~mm}$ using occlusal splint device for a period of 3 months (Fig 3). Crown lengthening procedure was performed on both maxillary and mandibular teeth and root canal treatment were done for selected teeth after healing of periodontal tissues. A tooth preparation with a circumferential chamfer margin configuration for metal-ceramic crowns was performed. Provisional restorations were fabricated from the diagnostic wax-up and they were cemented with zinc oxide eugenol temporary cement (Temp NE; 3M ESPE, St Paul, USA). The patient wore the provisional restorations at the new vertical dimension for 3 months. A custom incisal guide table was fabricated from the acrylic resin (Rapid Repair; Dentsply India, Gurgaon, India) to preserve the anterior guidance of provisional restorations for the fabrications of definitive restorations.

Shades for the final restorations were determined. Secondary impressions of the prepared maxillary and mandibular anterior teeth were made using polyvinyl siloxane impression material (Examix NDS, GC America Inc., USA) in special trays. Working casts were fabricated and mounted on the semiadjustable articulator using interocclusal records. Porcelain fused to metal (PFM) crowns (Ivoclar Vivadent) with occlusal porcelain, were fabricated according to the manufacturer recommendations. A

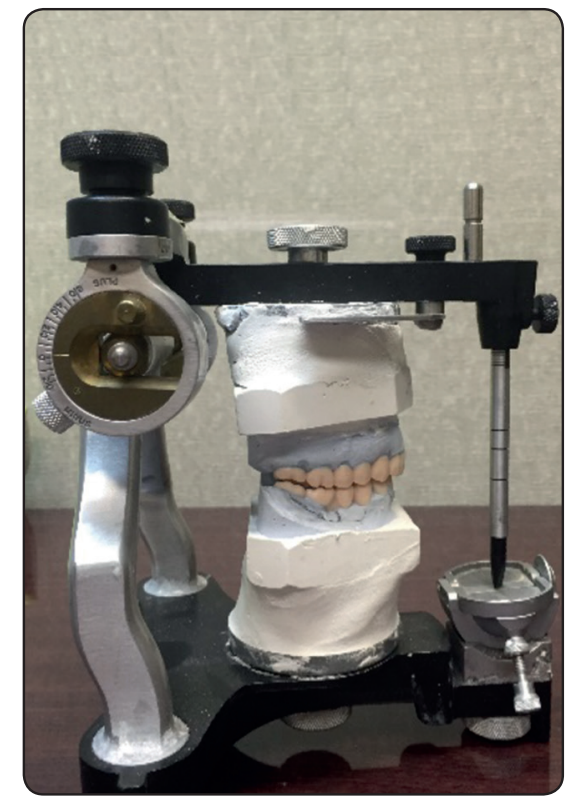

Fig. (2) Mounted diagnostic wax-up.

trial evaluation of the PFM crowns, prior to glazing, for final occlusal adjustment were performed. After glazing the crowns were cemented with glass ionomer cement (GC Fuji I, GC Corporation, Tokyo, Japan) according to manufacturer instructions (Fig 4). The patient was satisfied with the outcome of the treatment with regard to function and aesthetics. The patient was monitored at 3-month intervals for 1 year and then once a year for recall, and she has not experienced any complications since past 6 years except for the partial debonding of the crown replacing the right maxillary canine, which was rebounded in the same follow-up visit (Fig 5).

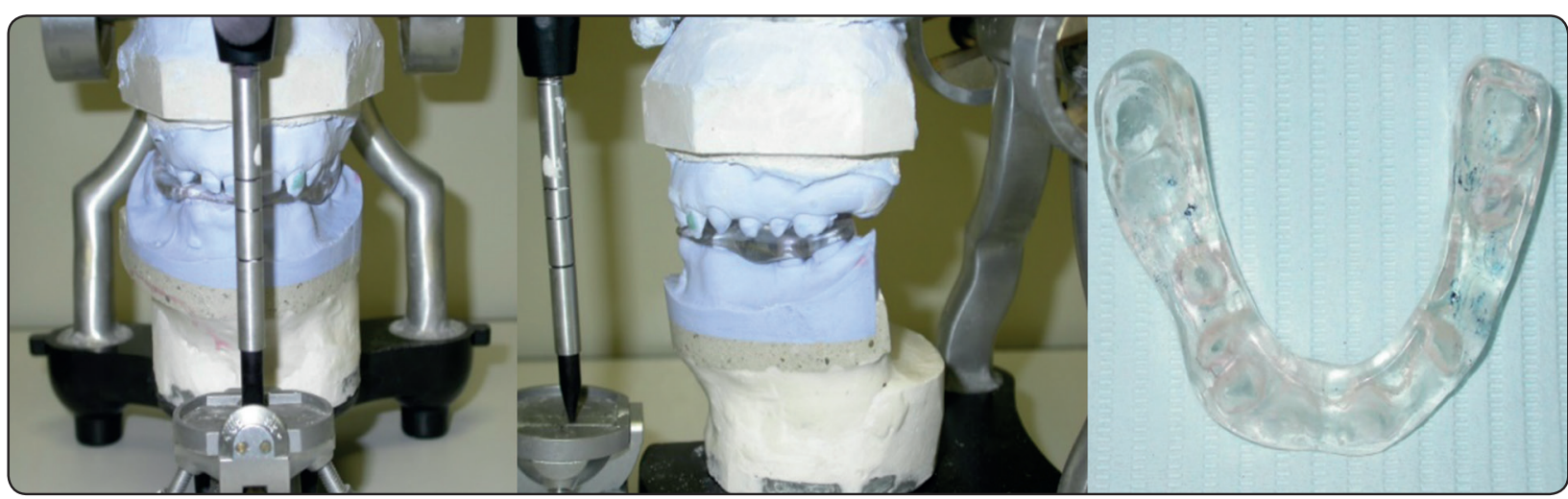

(a) (b) (c)

Fig. (3) Construction of occlusal splint device. 


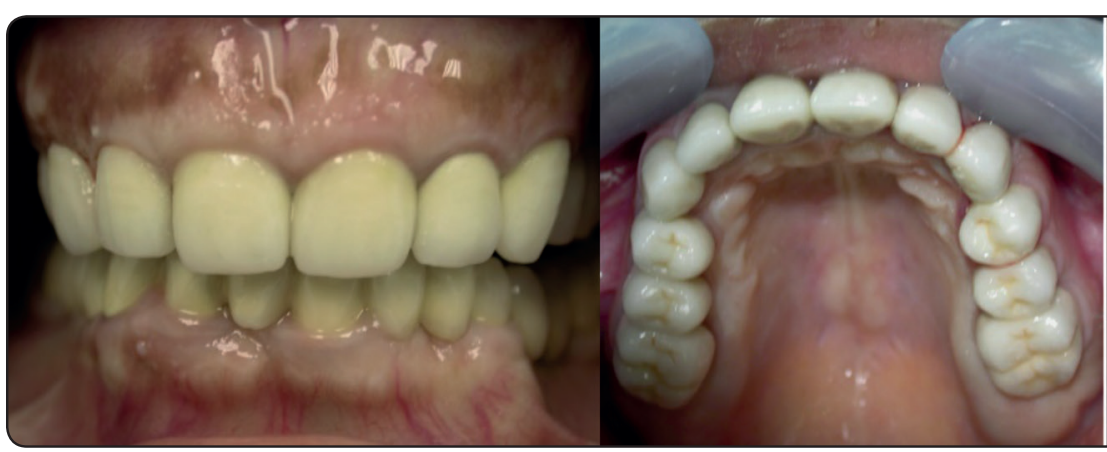

(a) (b)

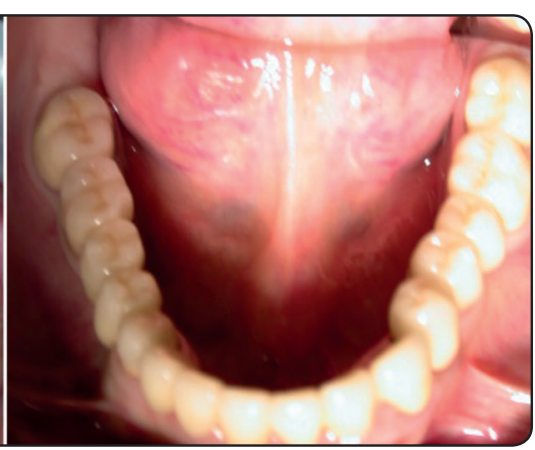

(c)

Fig. (4) Post-treatment intra-oral views (a) centric occlusion, (b) maxillary arch and (c) mandibular arch.

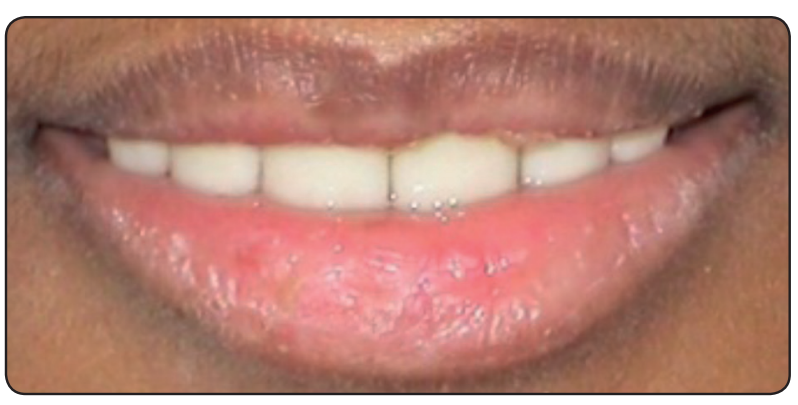

Fig. (5) Post- treatment extra-oral view

\section{DISCUSSION}

The dental management of the presented case was a challenging experience due to the medical condition of the patient and severely worn dentition. Close follow up with patient's hematologist before each dental visit was crucial to prepare the patient for various surgical and dental intervention. Blood transfusion and antibiotic coverage were indicated before some dental procedures according to the severity of dental intervention with the standard local anesthetic agents. Similar management were reported in several literatures ${ }^{(6,7,9,12)}$. Short appointments and stress-free, avoiding long and complicated procedures was followed during treatment.

The PFM fixed restorations were selected for the current patient due to the severely worn dentition and difficulty of establishing a thick gingival margin indicated for full ceramic restorations. In addition, the small size of the remaining dentition provided sufficient space for proper esthetic build up when using PFM. The metal- ceramic restorations were the treatment of choice of posterior dentition in several reports ${ }^{(13-18)}$. A full ceramic coverage was used in less severe cases with near normal dentition size ${ }^{(19-21)}$, with reported two fractured zirconia all crowns at 6 years follow-up ${ }^{(21)}$ and lack of bonding between dentin and zirconia crowns were also observed and resulted in microleakage and pulpal damage ${ }^{(21)}$. In the current case, the use of PFM crowns provided high retention in spite of the short clinical crowns and the use of glass-ionomer luting cement was successful in preserving adequate bond to tooth structure and prevention of teeth decay. Six years follow-up was considered successful with high patient satisfaction.

\section{CONCLUSION}

Dental management of sickle cell anemia patients requires a multidisciplinary approach with medical supervision to prevent any complication that might affect the patient's medical condition and the success of dental treatment. Porcelain fused to metal fixed restorations cemented with glass ionomer cement were successfully used to restore anterior and posterior dentition. 


\section{REFERENCES}

1. Kelleher M, Bishop K, Briggs P. Oral complications associated with sickle cell anemia: a review and case report. Oral Surgery, Oral Medicine, Oral Pathology, Oral Radiology, and Endodontology. 1996;82(2):225-8.

2. Rees DC, Williams TN, Gladwin MT. Sickle-cell disease. The Lancet. 2010;376(9757):2018-31.

3. Stuart MJ, Nagel RL. Sickle-cell disease. The Lancet. 2004;364(9442):1343-60.

4. Sams DR, Thornton JB, Amamoo PA. Managing the dental patient with sickle cell anemia: a review of the literature. Pediatric dentistry. 1990;12(5):316-20.

5. Sansevere JJ, Milles M. Management of the oral and maxillofacial surgery patient with sickle cell disease and related hemoglobinopathies. Journal of oral and maxillofacial surgery : official journal of the American Association of Oral and Maxillofacial Surgeons. 1993;51(8):912-6.

6. Piccin A, Fleming P, Eakins E, McGovern E, Smith OP, McMahon C. Sickle cell disease and dental treatment. Journal of the Irish Dental Association. 2008;54(2):75-9.

7. Acharya S. Oral and Dental Considerations in Management of Sickle Cell Anemia. International journal of clinical pediatric dentistry. 2015;8(2):141-4.

8. Mello SM, Paulo CAR, Alves C. Oral considerations in the management of sickle cell disease: a case report. Oral health and dental management. 2012;11(3):125-8.

9. Stanley AC, Christian JM. Sickle cell disease and perioperative considerations: review and retrospective report. Journal of oral and maxillofacial surgery : official journal of the American Association of Oral and Maxillofacial Surgeons. 2013;71(6):1027-33.

10. Passos CP, Santos PR, Aguiar MC, Cangussu MC, Toralles MB, da Silva MC, et al. Sickle cell disease does not predispose to caries or periodontal disease. Special care in dentistry : official publication of the American Association of Hospital Dentists, the Academy of Dentistry for the Handicapped, and the American Society for Geriatric Dentistry. 2012;32(2):55-60

11. Devine BP. What dentists should know about sickle cell disease. Texas dental journal. 2013;130(11):1123-7.
12. Bryant C, Boyle C. Sickle cell disease, dentistry and conscious sedation. Dental update. 2011;38(7):486-8, 91-2.

13. Ozturk N, Sari Z, Ozturk B. An interdisciplinary approach for restoring function and esthetics in a patient with amelogenesis imperfecta and malocclusion: a clinical report. The Journal of prosthetic dentistry. 2004;92(2):112-5.

14. Bouvier D, Duprez JP, Pirel C, Vincent B. Amelogenesis imperfecta - a prosthetic rehabilitation: A clinical report. The Journal of prosthetic dentistry. 1999;82(2):130-1.

15. Sholapurkar AA, Joseph RM, Varghese JM, Neelagiri K, Acharya SR, Hegde V, et al. Clinical diagnosis and oral rehabilitation of a patient with amelogenesis imperfecta: a case report. The journal of contemporary dental practice. 2008;9(4):92-8.

16. Yilmaz B, Oz U, Yilmaz HG. Interdisciplinary approach to oral rehabilitation of patient with amelogenesis imperfecta. The New York state dental journal. 2014;80(2):31-5.

17. Akin H, Tasveren S, Yeler DY. Interdisciplinary approach to treating a patient with amelogenesis imperfecta: a clinical report. Journal of esthetic and restorative dentistry : official publication of the American Academy of Esthetic Dentistry [et al]. 2007;19(3):131-5.

18. Kamble VD, Parkhedkar RD. Multidisciplinary approach for restoring function and esthetics in a patient with amelogenesis imperfecta: a clinical report. Journal of clinical and diagnostic research : JCDR. 2013;7(12):3083-5.

19. Millet C, Duprez JP, Khoury C, Morgon L, Richard B. Interdisciplinary Care for a Patient with Amelogenesis Imperfecta: A Clinical Report. Journal of prosthodontics : official journal of the American College of Prosthodontists. 2015;24(5):424-31.

20. Oliveira IK, Fonseca Jde F, do Amaral FL, Pecorari VG, Basting RT, Franca FM. Diagnosis and esthetic functional rehabilitation of a patient with amelogenesis imperfecta. Quintessence international (Berlin, Germany : 1985). 2011;42(6):463-9.

21. Siadat H, Alikhasi M, Mirfazaelian A. Rehabilitation of a patient with amelogenesis imperfecta using all-ceramic crowns: a clinical report. The Journal of prosthetic dentistry. 2007;98(2):85-8. 